\title{
Fair Heroes and Heroines, Dark Commoners-Colorism in Bangla Films
}

\author{
Swayamjit Saha ${ }^{1}$, Akash Roy Choudhury ${ }^{2}$, Garga Chatterjee ${ }^{3}$ \\ swayamjit.saha97@gmail.com ${ }^{1}$ arc1909@cse.jgec.ac.in² garga@isical.ac.in $^{3}$ \\ ${ }^{1}$ Department of Computer Science and Engineering, Swami Vivekananda Institute of Science \\ and Technology, West Bengal University of Technology, Kolkata, West Bengal, India. \\ ${ }^{2}$ Department of Computer Science and Engineering, Jalpaiguri Government Engineering \\ College, West Bengal University of Technology, West Bengal, India. ${ }^{3}$ Psychology Research \\ Unit, Indian Statistical Institute, Kolkata, West Bengal, India.
}

\begin{abstract}
:
In human society there exists colour based variation. In many ethnicities, colour variation is associated with beauty and attractiveness prevails in society. In dominant endogamous societies within an ethnicity, these characteristics are preserved and highly prioritized as markers of physical attractiveness in that ethnicity. Such dominant groups within an ethnicity dominate others, among other things, in terms of public portrayal, places, spaces and various opportunities on the basis of characteristics largely possessed and hence prized by dominant groups and are held up as aspiration goals to the rest. People who have fairer skin tone as compared to the darker skin tone tries to dominate other in terms of public portrayal. These public portrayals are clearly seen in the case of visual mass media like cinema and advertisement. This paper explores whether such skin colour tone based bias exists in case of Bangali ethnicity. The skin tone of heroes and heroines of popular Bangla films produced in West Bengal was taken as a proxy to explore the nature of skin colour tone based bias (if any), in case of the Bangla mother tongue population, the $5^{\text {th }}$ largest mother tongue population in the world. We found that the heroes and heroines have significantly lighter skin tones than other males and females of same ethnicity who are portrayed in a film. The results suggest that there exists significant skin colour based bias in the selection of heroes and heroines in Bangla films.
\end{abstract}

\section{Keywords:}

Tollywood, Skin tone, Colorism, Cie-L*a*b* colour space model, L*, Cinema, Bangla, Bangali 


\section{Introduction:}

Colorism exists in human society. Colorism can be seen in Indian marital mate selection process. Jha, Sonara et al stated in their paper how males were also more likely than females to state a preference for skin colour in their prospective brides, and to use qualitative words like beautiful and lovely to describe their preferred match ${ }^{5}$. In human society colour-based variation is synonymous to beauty, attractiveness. Fink, B. et al 2001 showed that skin texture plays a significant role in the judgment of female facial beauty ${ }^{3}$. In endogamous society, things which are perceived as high standards, are perpetuated as desirable and portrayals of what is desirable dominates public portrayals and cinemas. Hence rest of the society gets affected due to this practise as a fair chance is not provided to them and a gulf is created in between the portrayed-as-desirable and the rest. Margaret Hunter (2007) discussed about how colorism is a persistent problem in the people ofUSA ${ }^{2}$. It describes the experiences of African Americans, Latinos and Asian Americans with regard to skin colour. Study illustrated that light skinned people have clear advantages in areas like income, education, housing, and the marriage market as compared to dark-skinned people ${ }^{2}$.Maddox et al in their article showed reviews research examining racial phenotypicality bias-within-category stereotypes, prejudice, and discrimination based on race-related phenotypic characteristics of the face ${ }^{1}$. A literature review of research examining skin tone bias, drawing largely from work examining perceptions of Blacks in the United States, reveals that individuals with features typical of members of their racial category are perceived and treated more negatively by social perceivers ${ }^{1}$.

In India cinema is a mass media. Srinivas, L. showed that audiences show intensive reactions to popular Indian cinemas ${ }^{4}$. In Indian cinema theatres viewers frequently cheer and whistle, shout out to characters on-screen, throw coins at the screen in appreciative display and sing along with the soundtrack. Singh, P. discussed in their paper how the Indian film industry implemented psychological themes in their movies ${ }^{8}$. By means of cinema role models are created and idolized by the Indian people. Hence, the audience is fed ideas about beauty, attractiveness and other phenotypical characteristics. In these ways characteristics goes into desired list. Now if the role models are selected in the field of colorism inferiority complex arises on the non-shared candidates for public portrayal.

In India, various fairness creams are sold. Indian actors and actresses are modelling for the promotion of fairness creams. Discrimination based on colour based variation or colorism exists in India. Shevde, N. looked at the issues related to skin color in India by analysing how Fair \& Lovely skin-whitening cream is situated in the context of Indian culture, acts as a fetish through media, and is distributed to consumers ${ }^{6}$.

Since film is an effective communication media and colorism if practised in film industry can be dangerous for the society. Studies on the practise of colorism in various Indian language films and different ethnicities is lacking. For this reason we select Bangla language films the second largest language of India and explore the issue of colorism in Bangla highest grossing films of Tollywood industry in the last ten years. 


\section{Methods:}

Highest grossing Bangla movies of Tollywood industry for last ten years from 2009-2018 were taken in which there is a romantic connection between Hero and Heroine. The selected movies have a resolution of $1280 \times 720$ and a frame rate of $24 \mathrm{fps}$. The selected movies were trimmed keeping in mind some methodologies which are discussed below. Rest of the unwanted scenes were deleted. The selected scenes were trimmed keeping in mind that there is Hero and at least one male side character or Heroine with at least one female side character in Indian Bangla soil. No foreign male and female side characters are taken into consideration for skin colour tone extraction from the selected scenes. The selected scenes consisting of all the considered characters should be recorded in natural lighting condition that is during day time. The scenes were extracted keeping in mind that the glabella portion of the considered characters are visible that is the middle portion of the foreheads from where the skin tone colour was extracted. From the selected scenes maximum 5 side characters of the same sex were chosen randomly to compare with Hero / Heroine if the number of side characters exceeds 5. Among all the scenes of variable time length, the scene with lowest time length was considered. The number of frames to be taken from that scene was determined by multiplying the length of the scene (in Seconds) with 5 and taking the floor value of that number. If a scene in any movie had less than 24 frames in it, then for that movie 5 frames were taken from each scene. The same number of equally spaced frames (with respect to time) were extracted from the rest of the scenes. From those extracted frames the L value of the Cie-L*a*b* colour space values of skin tones were compared to see the difference in skin tones between the leading cast and the rest. The skin tone from where $\mathrm{L}$ value of the Cie$\mathrm{L}^{*} \mathrm{a} \mathrm{b}^{*}$ colour space is extracted should be natural and should not consist of external colours and tattoos. After getting the $\mathrm{L}^{*}$ values of the main and side characters for a frame, we averaged the $L^{*}$ values of the side characters of same gender and compared it with the $\mathrm{L}$ value of the main character of that particular gender.

The highest grossing Bangla films of Tollywood industry for last ten years (2009-2018) according to Wikipedia are as follows: Paran Jai Jaliya Re (2009), Bolo Na Tumi Aamar (2010), Paglu (2011), Awara (2012), ChanderPahar (2013), Bindaas (2014), Shudhu Tomari Jonyo (2015), Praktan (2016), Amazon Obhijaan (2017) and Hoichoi Unlimited (2018).

Indoor scenes are excluded from our experiment since it is possible to elevate the skin colour tone by means of artificial lightning. Thus, for attaining the best results we chose frames where natural lighting is available that is during daytime. Also, if any particular frame consisted of more than five side characters, we chose the five nearest to the leading cast of their gender as they will have the same sunlight exposure.

While doing the experiment it was observed that some scenes consisted of high time length as compared to other scenes which consisted of shorter time length. To avoid any kind of anomaly equal number of frames were taken from every scene.

For our convenience we preferred Cie- $\mathrm{L}^{*} \mathrm{a} \mathrm{b}^{*}$ colour space model over RGB colour space model. RGB colour space expresses as a linear accumulation of three values Red, Green and Blue whereas the Cie- $L^{*} a^{*} b^{*}$ model expresses it using $L^{*}$ for Black to White, $a *$ for Green 
to Red and $b^{*}$ for blue to yellow in a three-dimensional linear real number space ${ }^{7}$. We extracted the $\mathrm{L}^{*}$ value of Cie-L*a*b* colour space model to evaluate the luminance factor of the leading cast with respect to the side characters.

\section{Results:}

The table below summarizes the results that we observed. As it can be seen that for $66.67 \%$ of the frames with heroes in them, the heroes have higher $\mathrm{L}$ values compared to male side characters and for $74.73 \%$ of the frames with heroines in them, the heroines have higher $\mathrm{L}$ values with respect to the female side characters.

The desired parameters were calculated by dividing the $\mathrm{L}^{*}$ value of $\mathrm{Cie}-\mathrm{L} * \mathrm{a} * \mathrm{~b} *$ colour space model of the leading cast by the average $\mathrm{L}^{*}$ value of the side characters of that particular gender. The parameters were plotted for every frame of the particular movie. The results are as shown below.

Any point that is below the straight line $Y=1$ signifies the hero or heroine in that frame have lower luminance factor $\mathrm{L}^{*}$ as compared to the respective side characters and correspondingly any point above the straight line is considered that the hero or heroine has higher $\mathrm{L}^{*}$ value as compared to the respective side characters.

Graph plots between ratio of $\mathrm{L}^{*}$ value of Heroine with respect to female side characters and number of frames cannot be done for the films Chander Pahar and Amazon Obhijaan since the actress with whom hero had a romantic connection was of different ethnicity. Hence our condition was not matched which stated that characters of only Bangali ethnicity is to be considered. Graph plot between ratio of $\mathrm{L}^{*}$ value of Heroine with respect to female side characters and number of frames cannot be done for the film Shudhu Tomari Jonyo since all the scenes that consisted of heroine and female side characters were shot under artificial lighting conditions. 


\begin{tabular}{|c|c|c|c|c|c|c|}
\hline $\begin{array}{c}\text { Names of highest } \\
\text { grossing films year- }\end{array}$ & $\begin{array}{c}\text { Total } \\
\text { number } \\
\text { of } \\
\text { frames } \\
\text { with } \\
\text { hero }\end{array}$ & $\begin{array}{c}\text { Total } \\
\text { number } \\
\text { of } \\
\text { frames } \\
\text { with } \\
\text { heroine }\end{array}$ & $\begin{array}{c}\text { Number } \\
\text { of frames } \\
\text { where } \\
\text { hero has } \\
\text { higher L } \\
\text { value }\end{array}$ & $\begin{array}{c}\text { Number } \\
\text { of frames } \\
\text { where } \\
\text { heroine } \\
\text { has } \\
\text { higher L } \\
\text { value }\end{array}$ & $\begin{array}{c}\text { Number } \\
\text { of frames } \\
\text { with more } \\
\text { than 5 } \\
\text { male side } \\
\text { characters }\end{array}$ & $\begin{array}{c}\text { Number } \\
\text { of frames } \\
\text { with more } \\
\text { than 5 } \\
\text { female } \\
\text { side } \\
\text { characters }\end{array}$ \\
\hline Paran Jai Jaliya Re & 6 & 50 & 6 & 34 & 0 & 0 \\
\hline $\begin{array}{c}\text { Bolo Na Tumi } \\
\text { Aamar }\end{array}$ & 63 & 56 & 44 & 51 & 0 & 2 \\
\hline Paglu & 68 & 22 & 48 & 15 & 3 & 0 \\
\hline Awara & 40 & 2 & 33 & 1 & 0 & 0 \\
\hline ChanderPahar & 30 & 0 & 16 & 0 & 2 & 0 \\
\hline Bindaas & 149 & 15 & 100 & 13 & 8 & 0 \\
\hline ShudhuTomariJonyo & 45 & 0 & 19 & 0 & 0 & 0 \\
\hline Praktan & 15 & 40 & 7 & 24 & 0 & 0 \\
\hline Amazon Obhijaan & 25 & 0 & 20 & 0 & 0 & 0 \\
\hline Hoichoi Unlimited & 66 & 1 & 45 & 1 & 0 & 0 \\
\hline Total & 507 & 186 & 338 & 139 & 13 & 2 \\
\hline
\end{tabular}

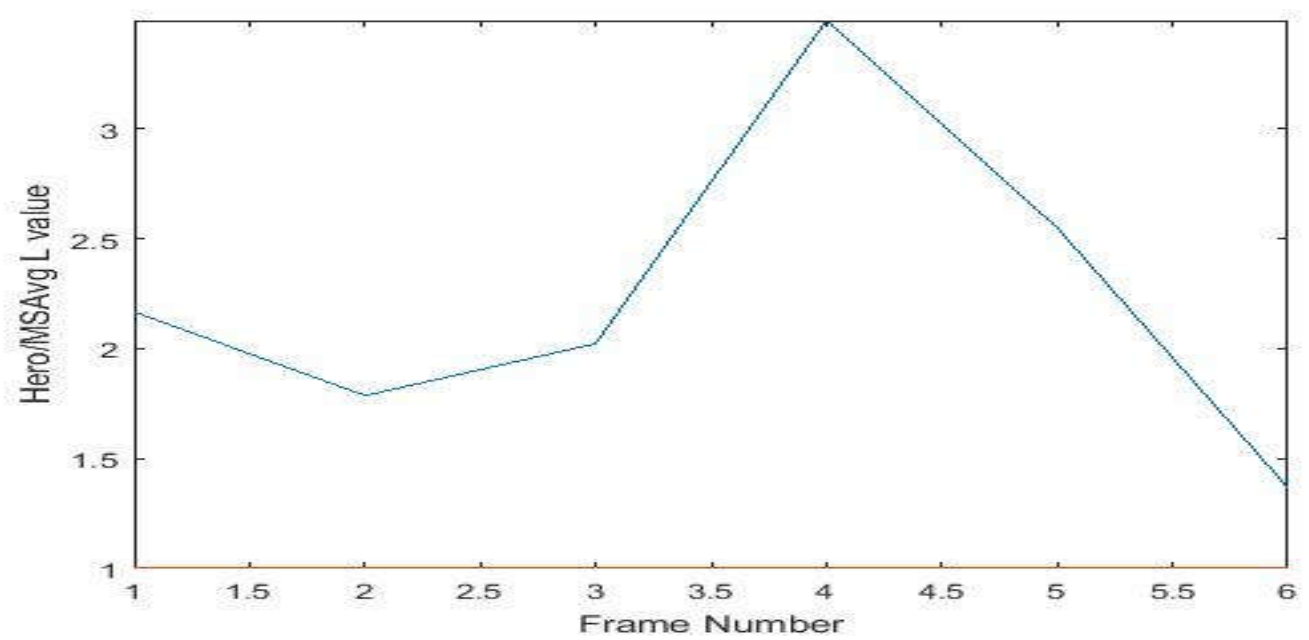

Figure 1 showing graph plot between $L^{*}$ ratio of Hero with respect to male side characters and number of frames of the film Paran Jai Jaliya Re for the year 2009. Result shows hero had fairer skin tone than the male side characters in all the frames 


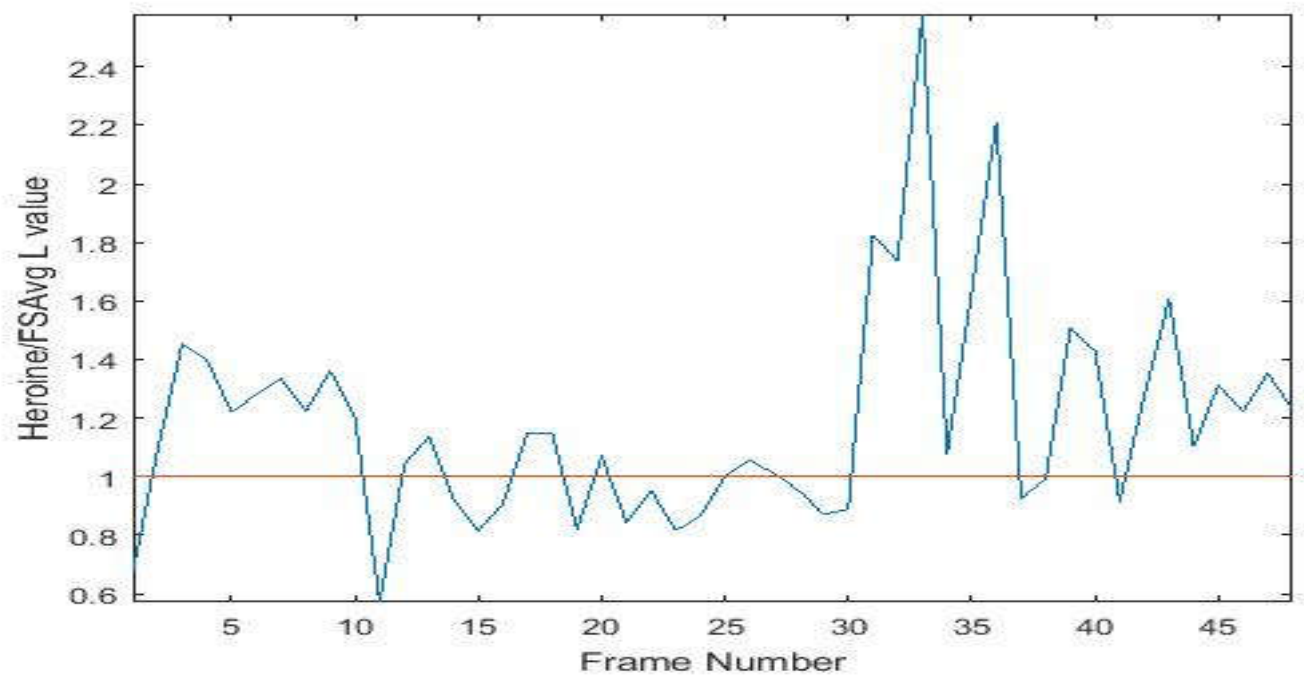

Figure 2 showing graph plot between $\mathrm{L}^{*}$ ratio of Heroine with respect to female side characters and number of frames of the film Paran Jai Jaliya Re for the year 2009. Result shows heroine had fairer skin tone than female side characters in majority of the considered frames.

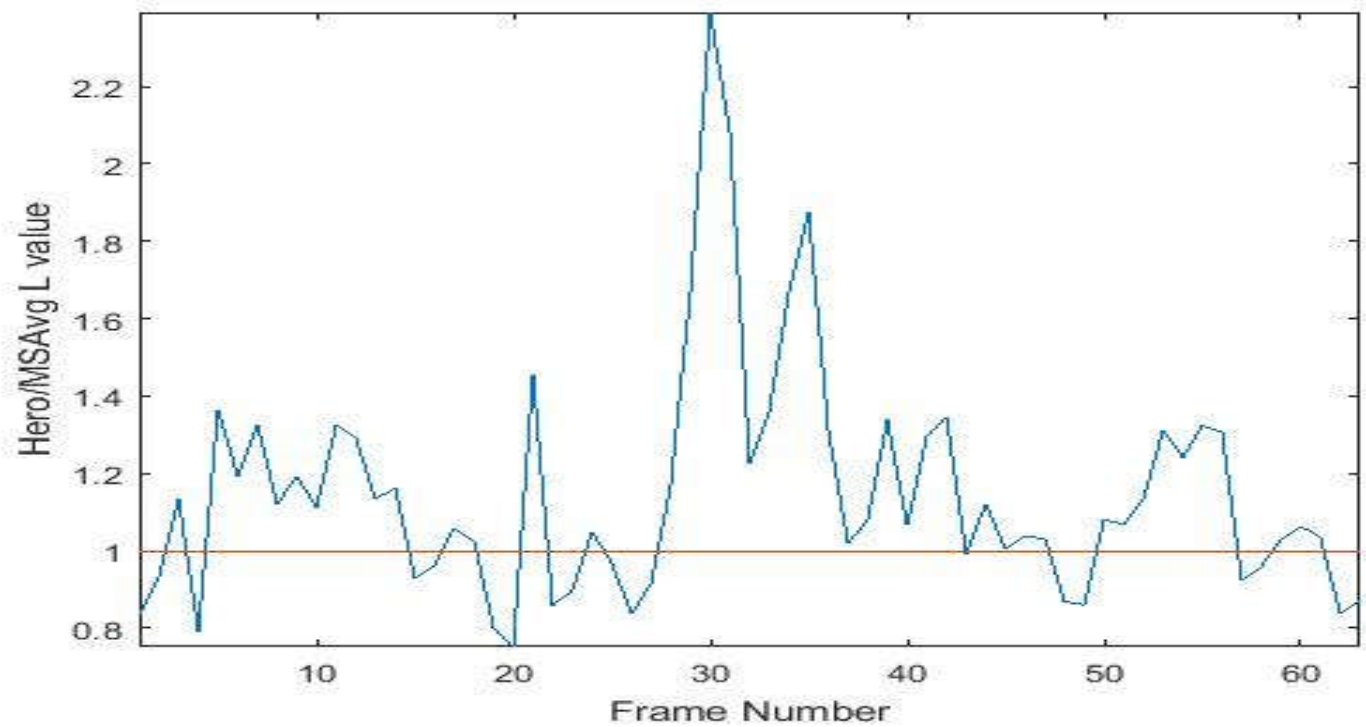

Figure 3 showing graph plot between $\mathrm{L}^{*}$ ratio of Hero with respect to male side characters and number of frames of the film Bolo Na Tumi Aamar for the year 2010. Result shows hero had fairer skin tone than male side characters in majority of the considered frames. 


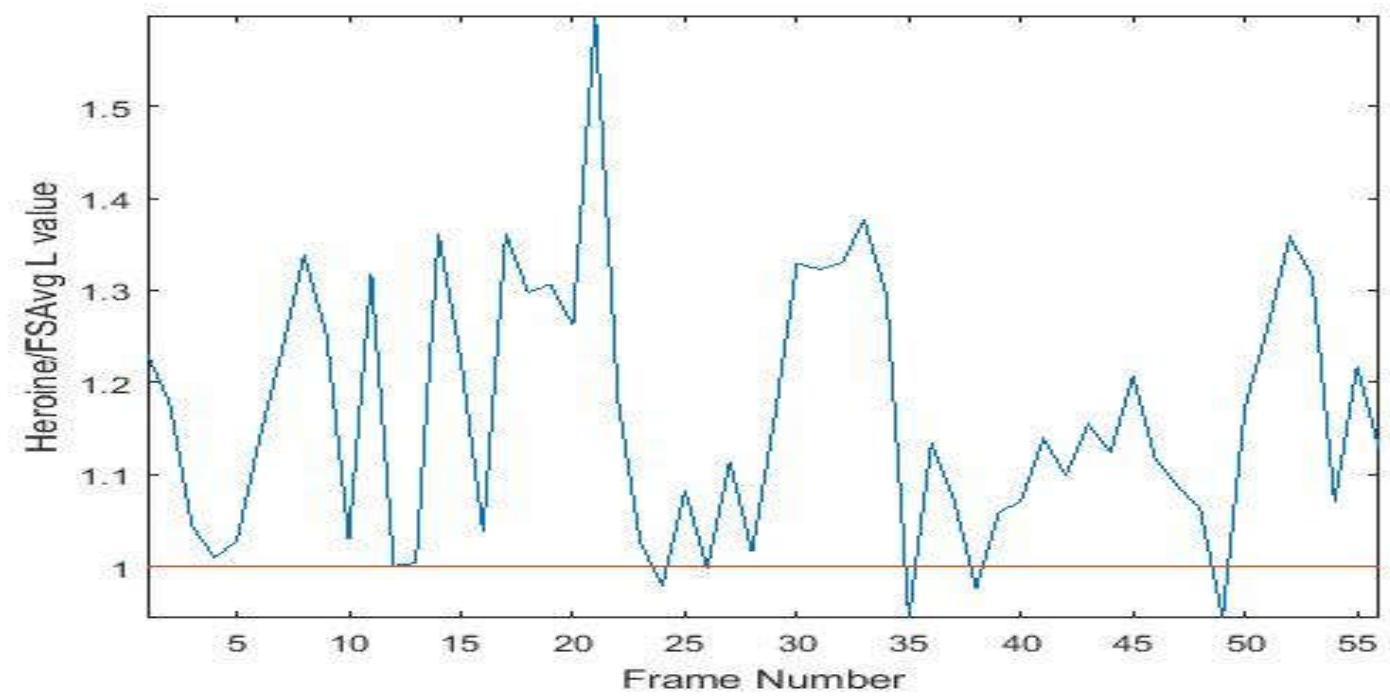

Figure 4 showing graph plot between $\mathrm{L}^{*}$ ratio of Heroine with respect to female side characters and number of frames of the film Bolo Na Tumi Aamar for the year 2010. Result shows heroine had fairer skin tone than female side characters in majority of the considered frames.

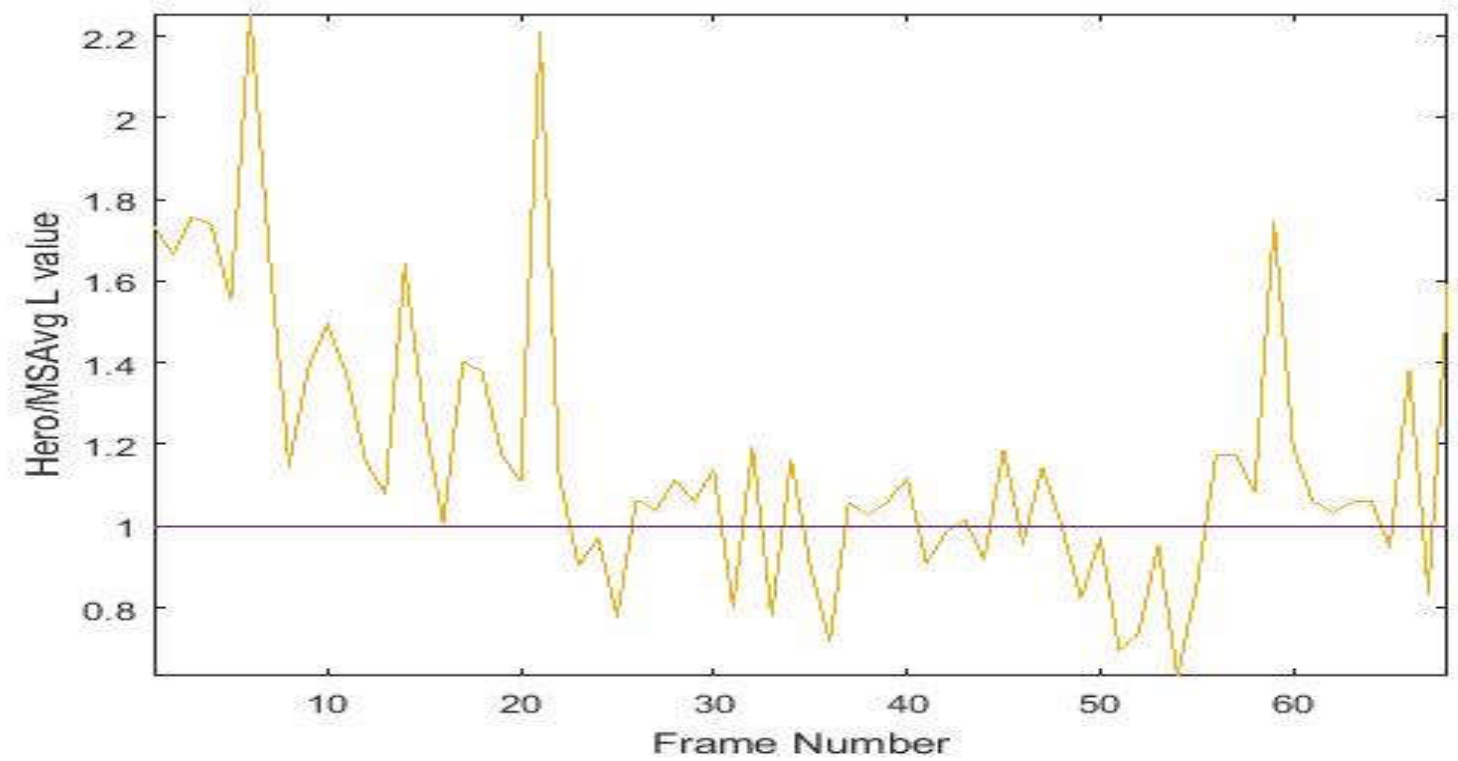

Figure 5 showing graph plot between $L^{*}$ ratio of Hero with respect to male side characters and number of frames of the film Paglu for the year 2011. Result shows hero had fairer skin tone than male side characters in majority of the considered frames. 


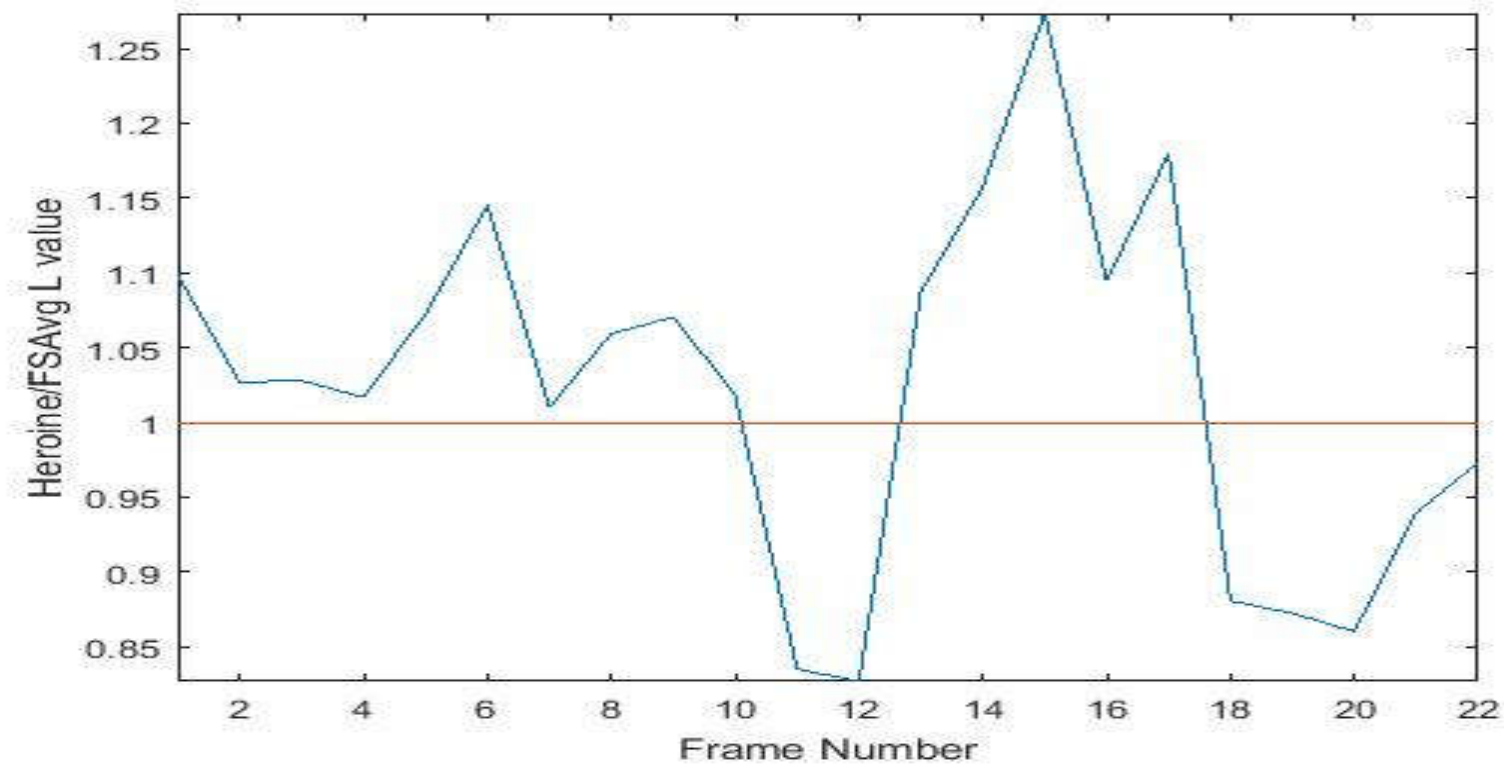

Figure 6 showing graph plot between $L^{*}$ ratio of Heroine with respect to female side characters and number of frames of the film Paglu for the year 2011. Result shows heroine had fairer skin tone than female side characters in majority of the considered frames.

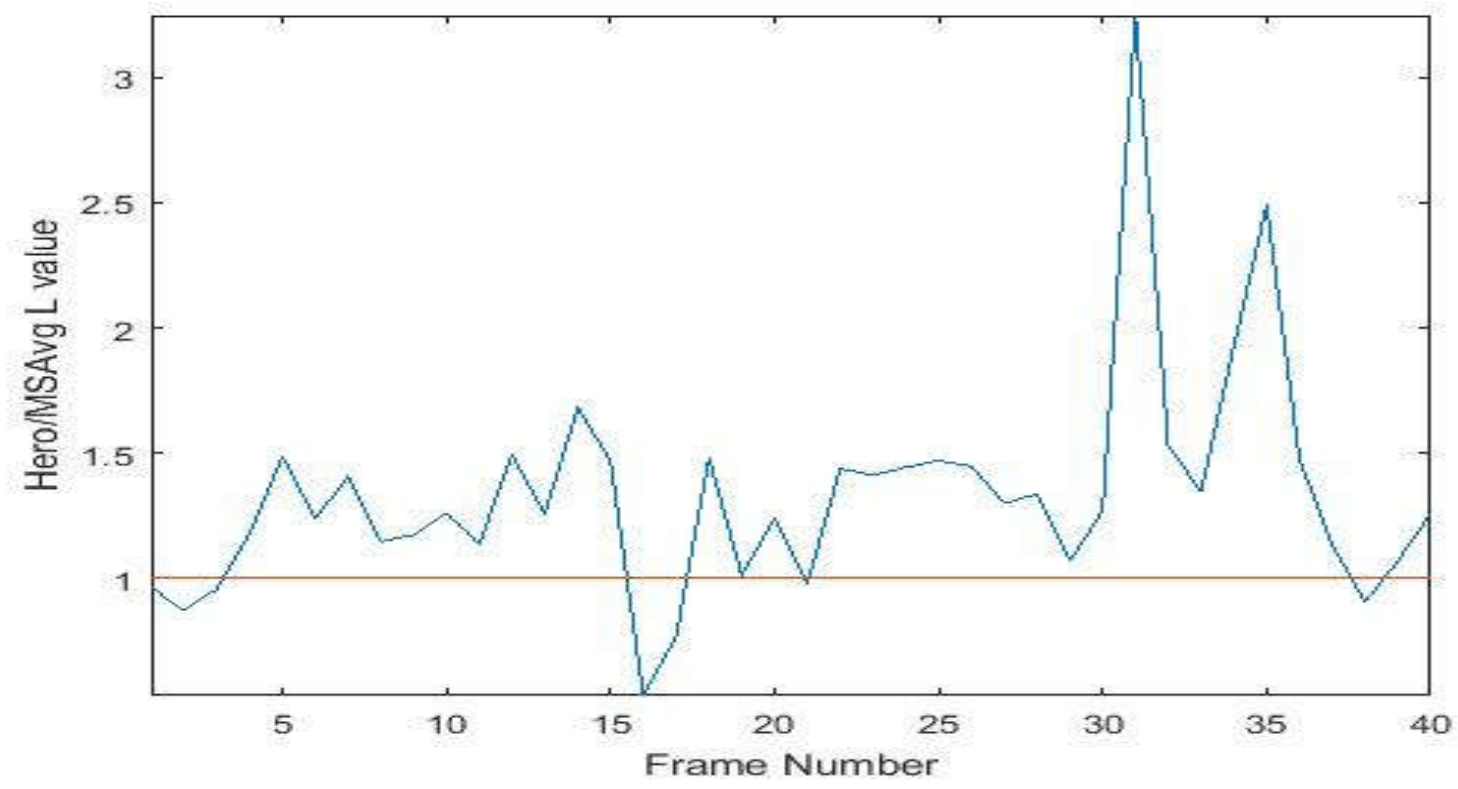

Figure 7 showing graph plot between $\mathrm{L}^{*}$ ratio of Hero with respect to male side characters and number of frames of the film Awara for the year 2012. Result shows hero had fairer skin tone than male side characters in majority of the considered frames. 


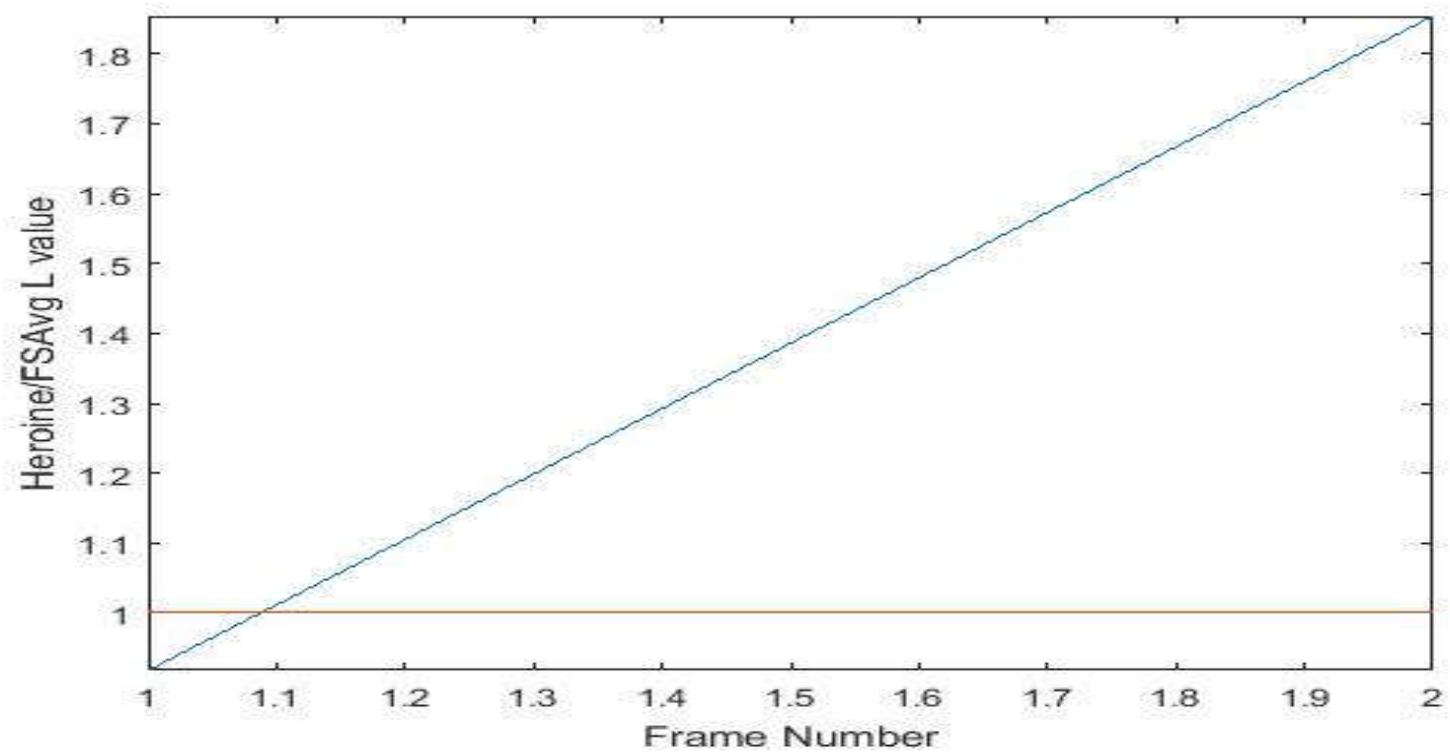

Figure 8 showing graph plot between $L^{*}$ ratio of Heroine with respect to female side characters and number of frames of the film Awara for the year 2012. Result shows heroine had fairer skin tone than female side characters in half of the considered frames.

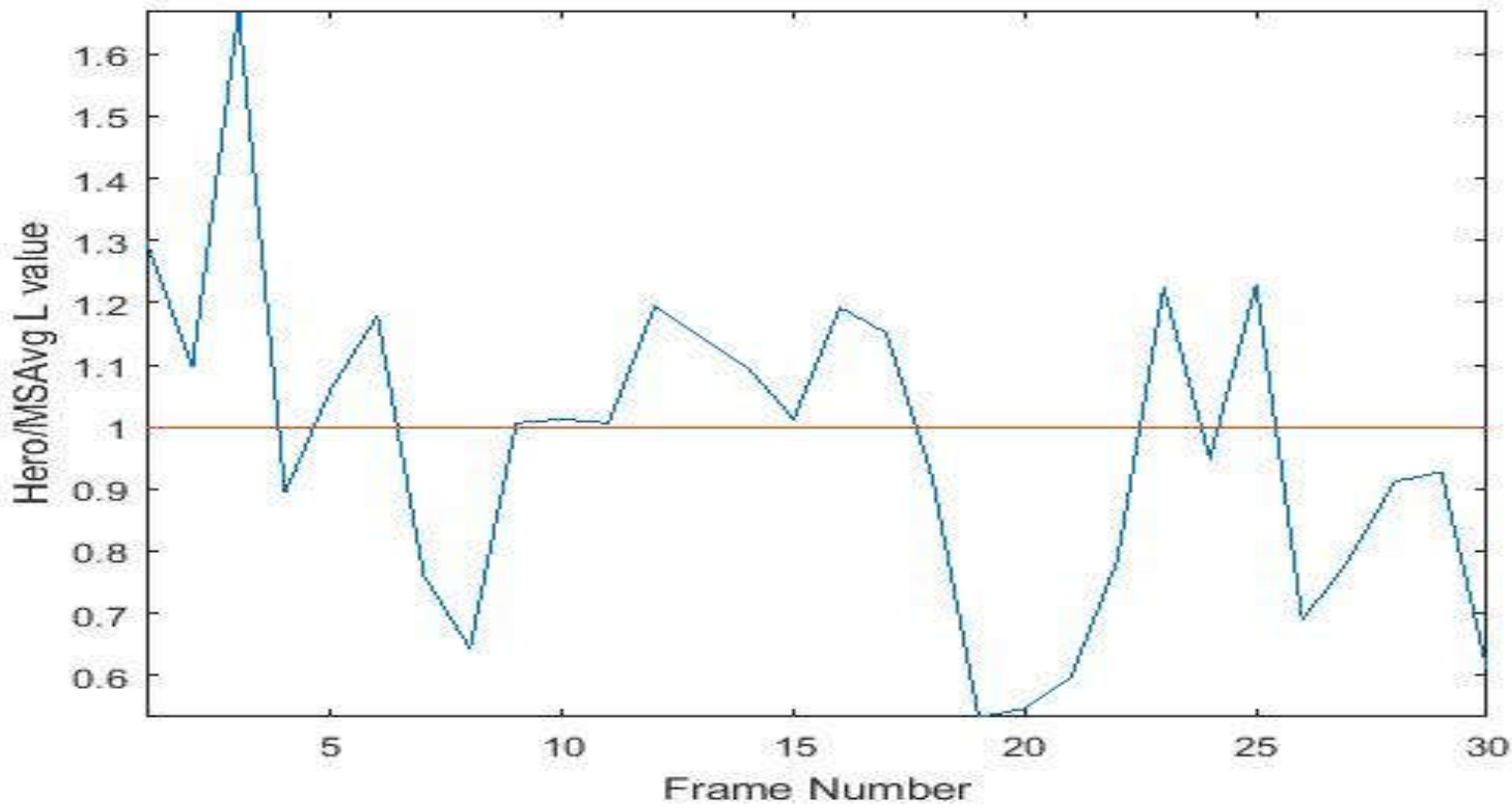

Figure 9 showing graph plot between $\mathrm{L}^{*}$ ratio of Hero with respect to male side characters and number of frames of the film Chander Pahar for the year 2013. Result shows hero had fairer skin tone than male side characters in majority of the considered frames. 


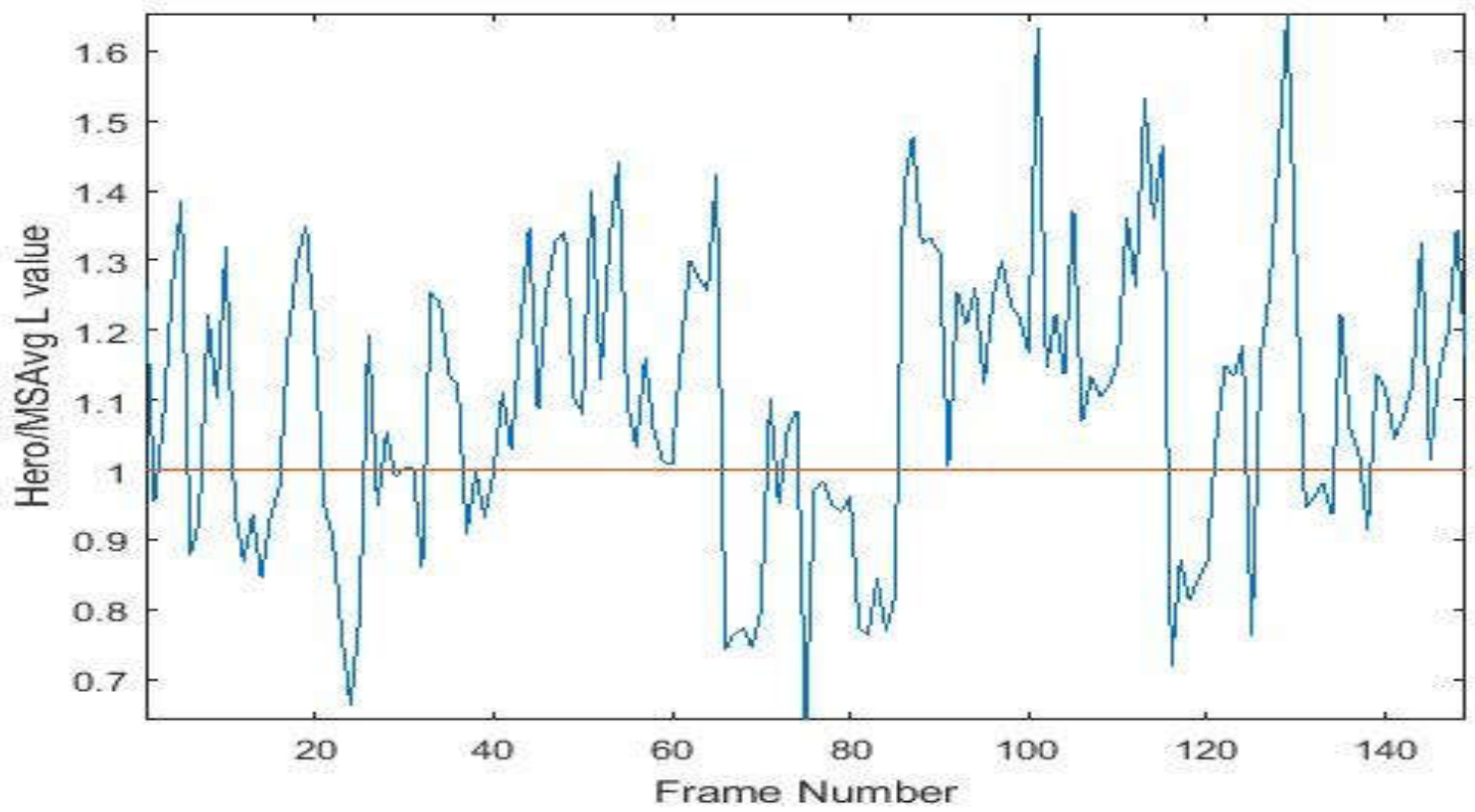

Figure 10 showing graph plot between $\mathrm{L}^{*}$ ratio of Hero with respect to male side characters and number of frames of the film Bindaas for the Year 2014. Result shows hero had fairer skin tone than male side characters in majority of the considered frames.

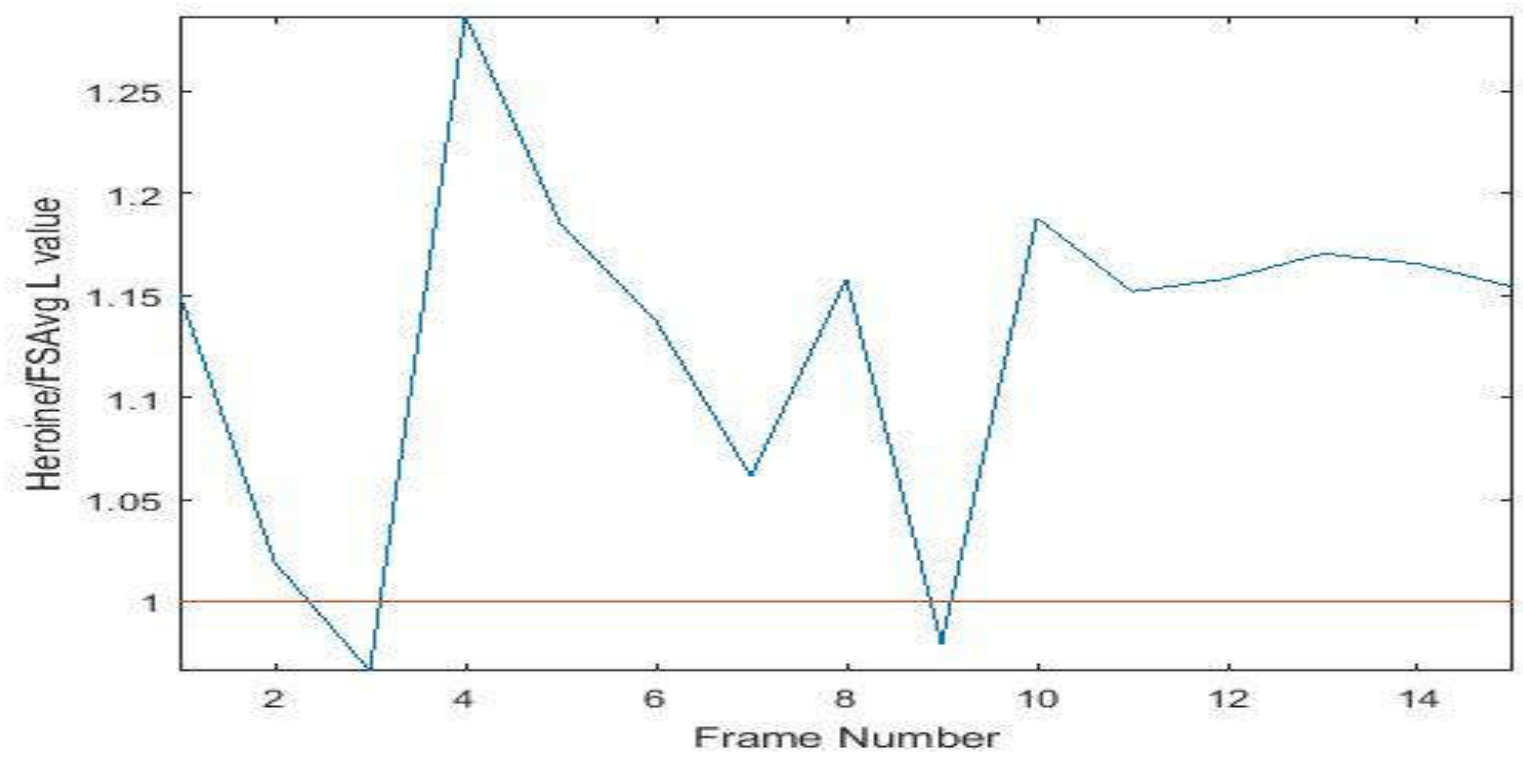

Figure 11 showing graph plot between $\mathrm{L}^{*}$ ratio of Heroine with respect to female side characters and number of frames of the film Bindaas for the year 2014. Result shows heroine had fairer skin tone than female side characters in majority of the considered frames. 


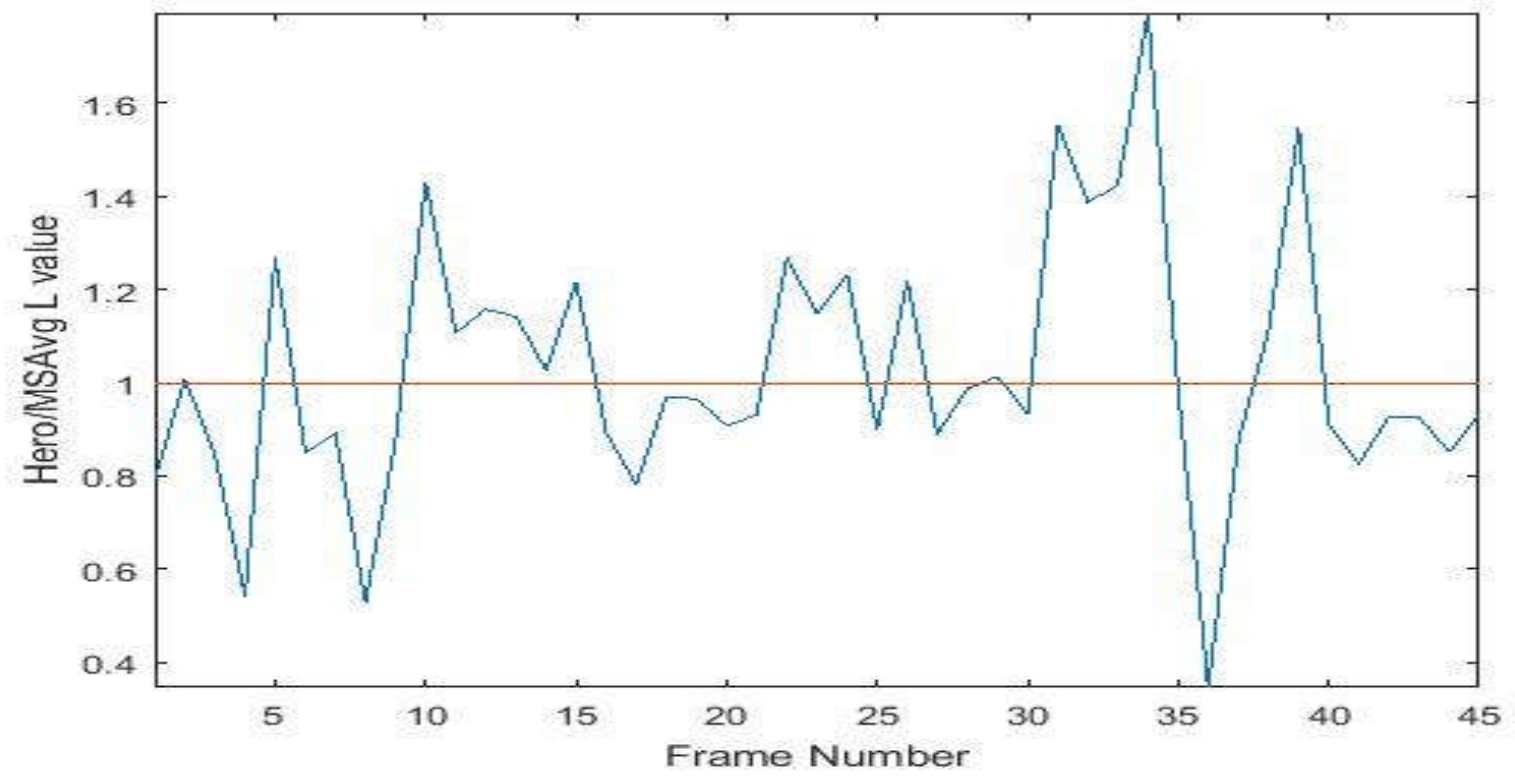

Figure 12 showing graph plot between $L^{*}$ ratio of Hero with respect to male side characters and number of frames of the film Shudhu Tomari Jonyo for the year 2015. Result shows average skin tone of side characters had fairer skin tone than hero in majority of the considered frames.

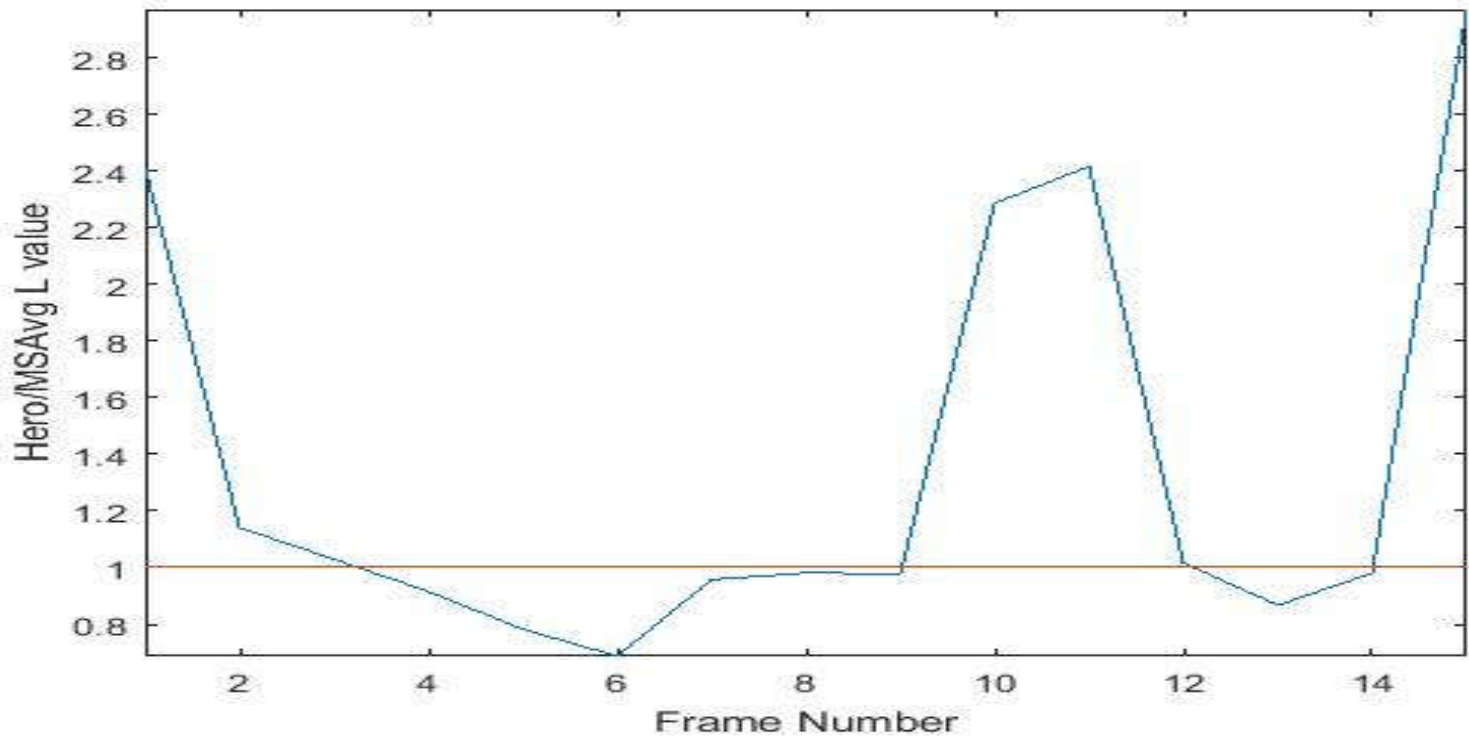

Figure 13 showing graph plot between $\mathrm{L}^{*}$ ratio of Hero with respect to male side characters and number of frames of the film Praktan for the year 2016. Result shows hero had fairer skin tone than male side characters in almost half of the considered frames. 


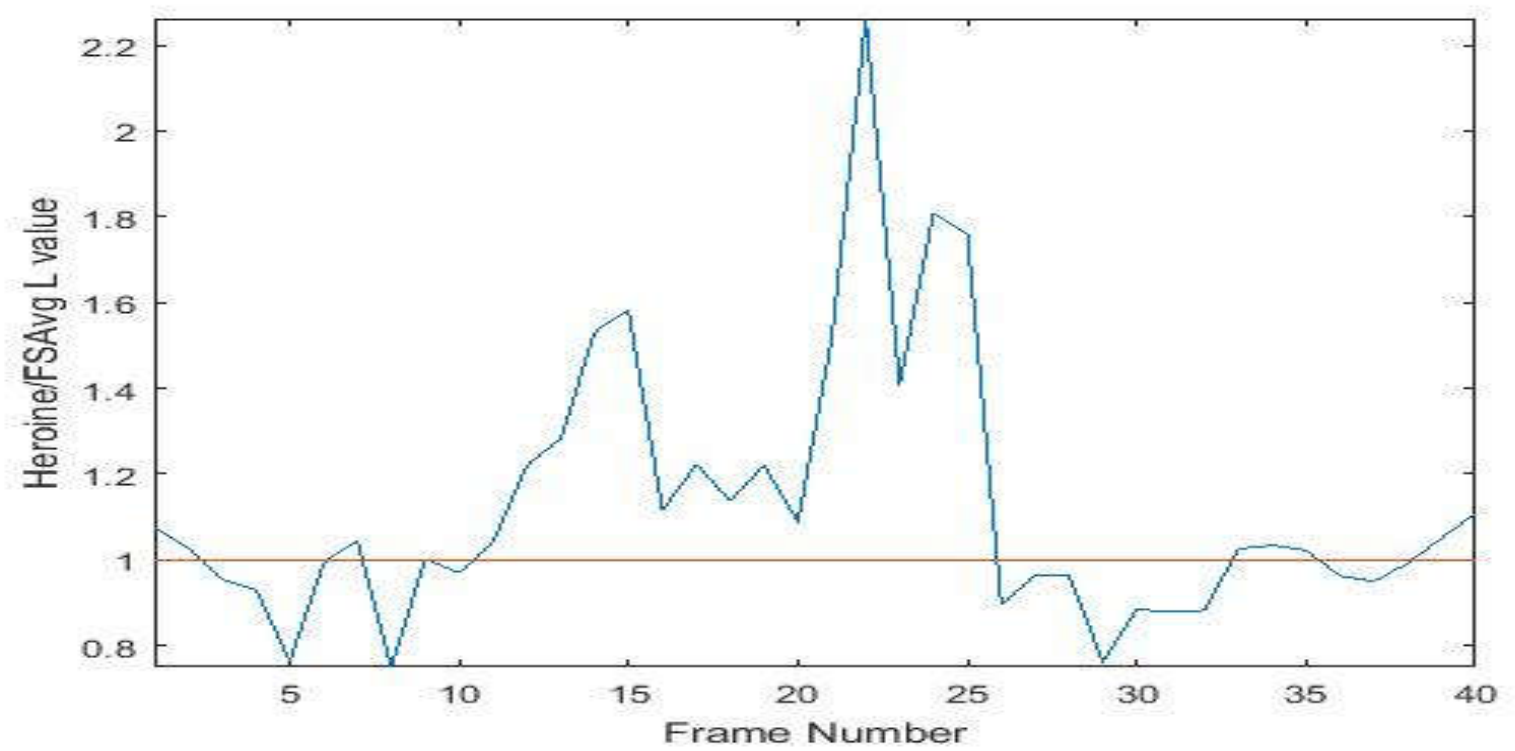

Figure 14 showing graph plot between $\mathrm{L}^{*}$ ratio of Heroine with respect to female side characters and number of frames of the film Praktan for the year 2016. Result shows heroine had fairer skin tone than female side characters in majority of the considered frames.

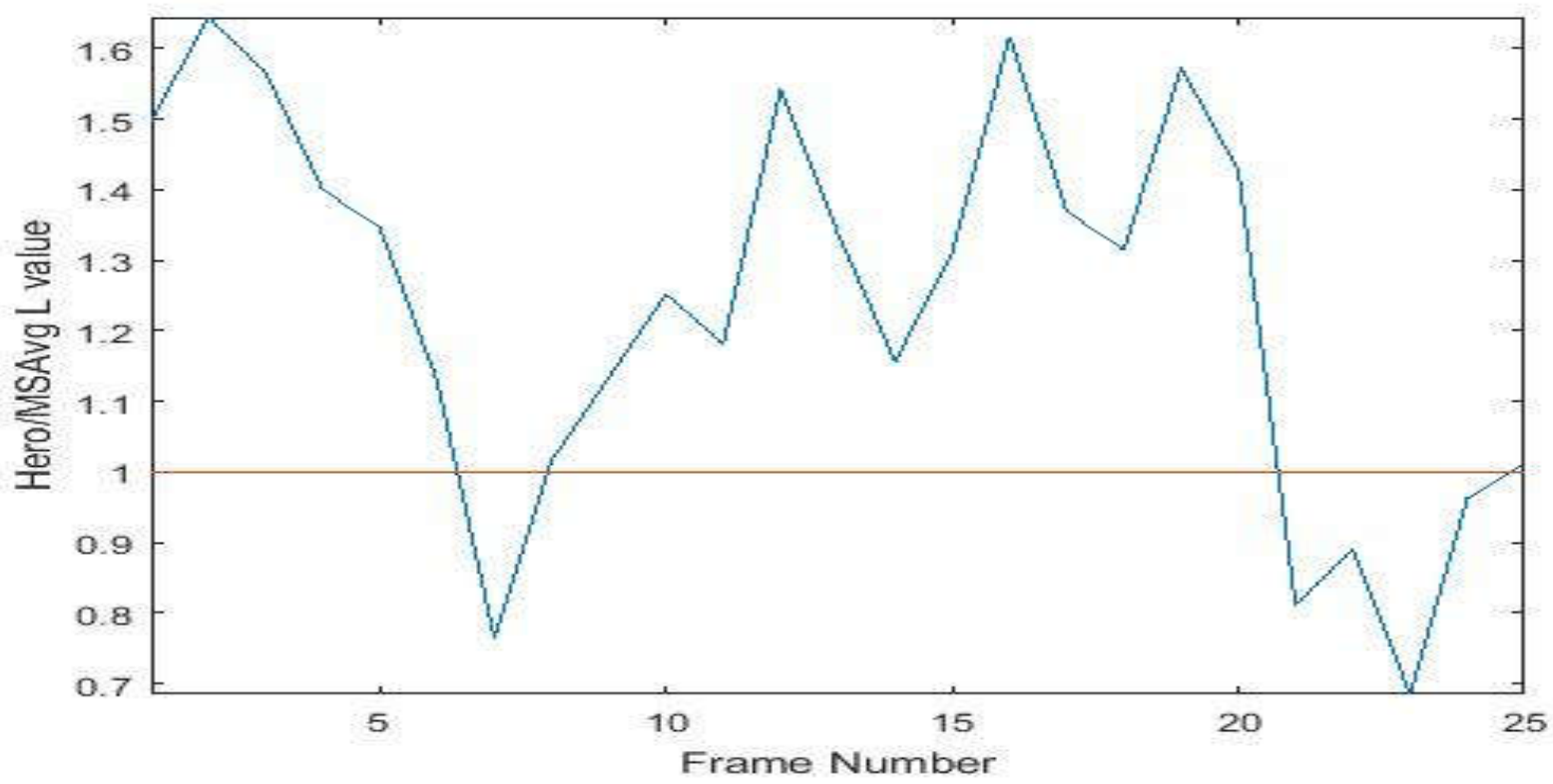

Figure 15 showing graph plot between $\mathrm{L}^{*}$ ratio of Hero with respect to male side characters and number of frames of the film Amazon Obhijaan for the year 2017. Result shows hero had fairer skin tone than male side characters in majority of the considered frames. 


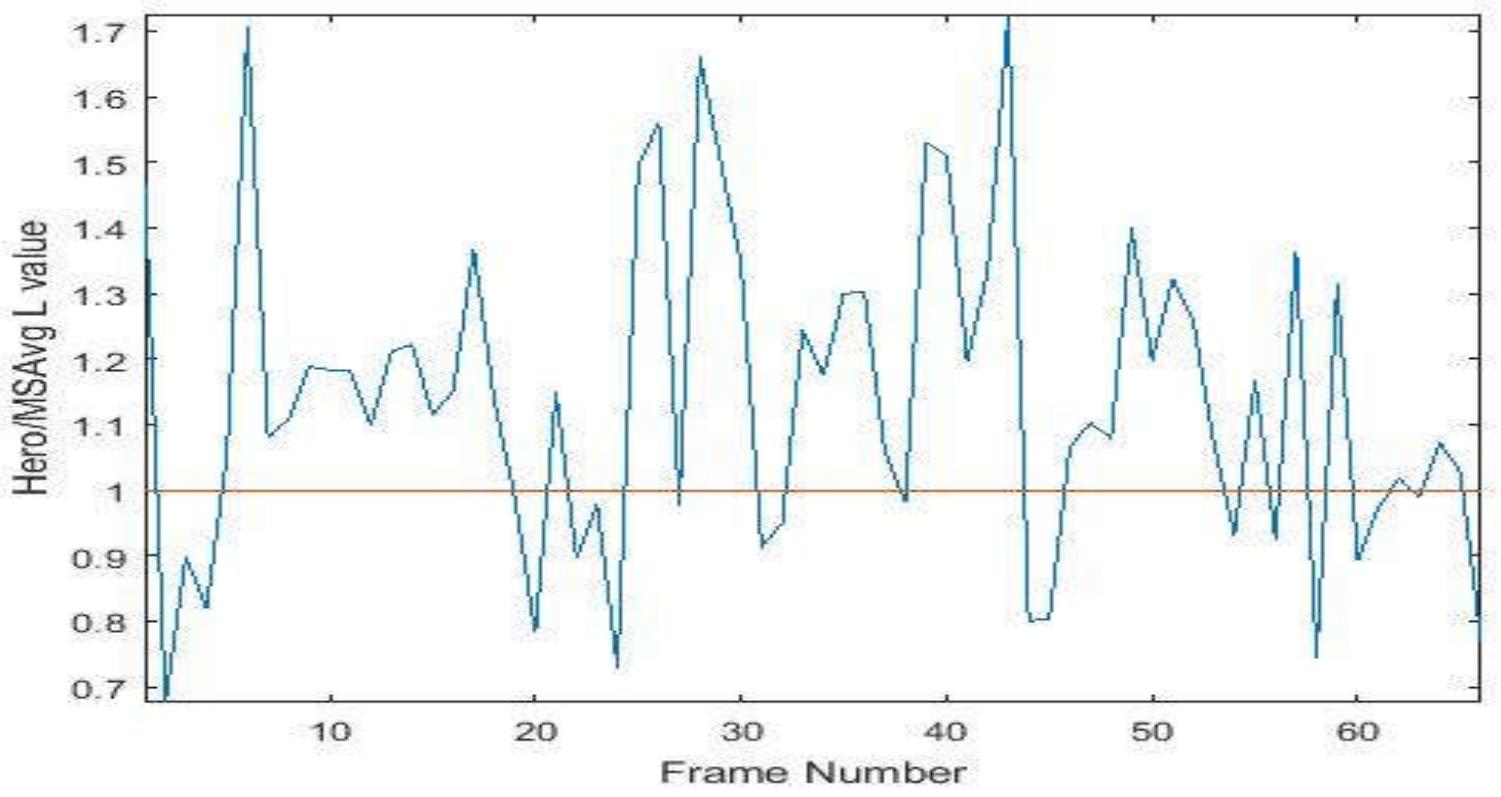

Figure 16 showing graph plot between $\mathrm{L}^{*}$ ratio of Hero with respect to male side characters and number of frames of the film Hoichoi Unlimited for the year 2018. Result shows hero had fairer skin tone than male side characters in majority of the considered frames.

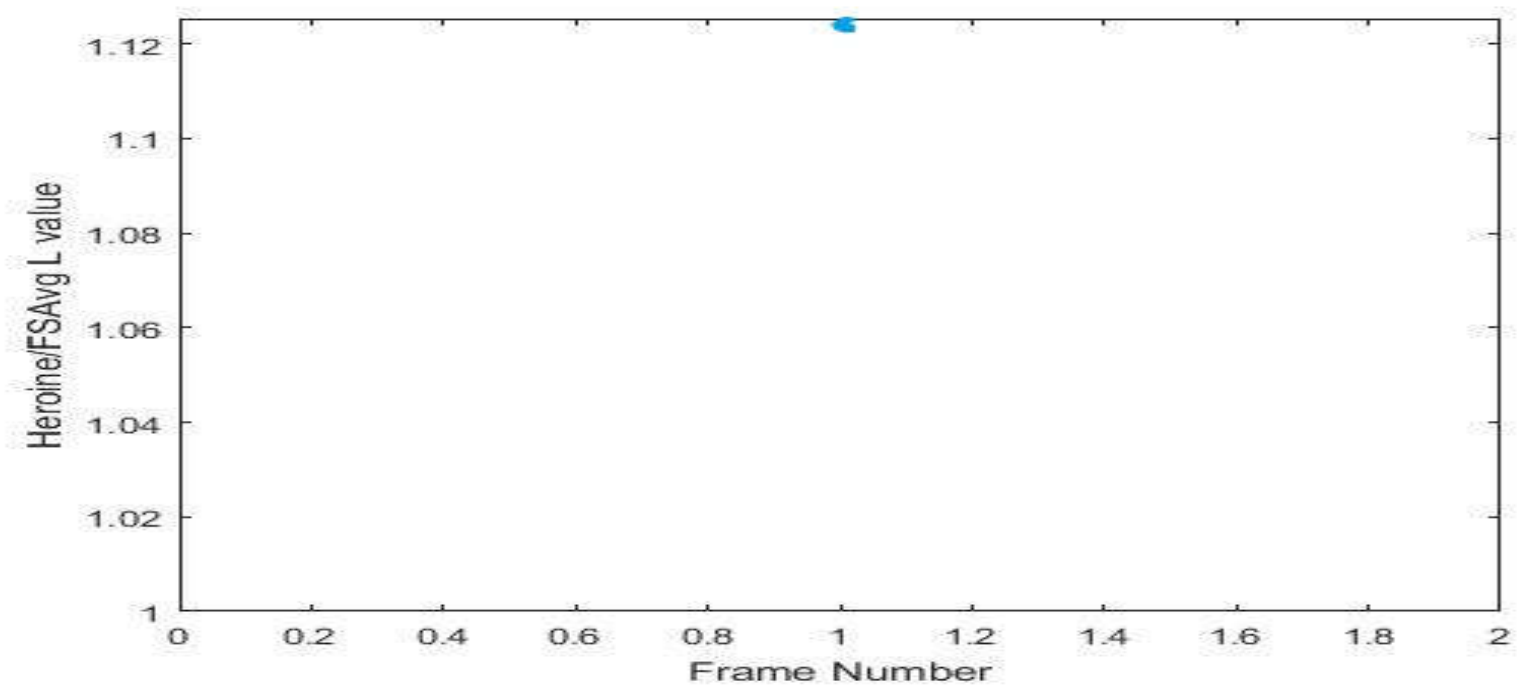

Figure 17 showing graph plot between $\mathrm{L}^{*}$ ratio of Heroine with respect to female side characters and number of frames of the film Hoichoi Unlimited for the year 2018. Result shows heroine had fairer skin tone than female side characters in the considered frame. 
Hero/MSAvg and Heroine/FSAvg L* values of Cie-L*a*b* colour model are used since they do not have any units. Also, if the values are greater than 1 we can infer that the hero or heroine has fairer skin tone as compared to the respective side characters.

Also, one-tailed t test is performed to find evidence of a significant difference between the population mean and a hypothesized value (1-sample $t)$. The $t$-value measures the size of the difference relative to the variation in our sample data. The greater the magnitude of $t$ value, the greater the evidence against the null hypothesis. This means there is greater evidence that there is a significant difference. The closer $\mathrm{T}$ is to 0 , the more likely there isn't a significant difference. The value $p$ infers the probability of finding $t$-values when sampling from the same population. The value NA infers that no data is found for that particular scenario. We have hypothesized the significance level to be lesser than 0.05 that is an accuracy of more than $95 \%$ and degrees of freedom to be 120 .

\begin{tabular}{|c|c|c|c|c|}
\hline Name of film & $\begin{array}{l}\text { Hero/MSAvg t } \\
\text { value }\end{array}$ & $\begin{array}{l}\text { Hero/MSAvg p } \\
\text { value }\end{array}$ & $\begin{array}{l}\text { Heroine/FSAvg } \\
\text { t value }\end{array}$ & $\begin{array}{l}\text { Heroine/FSAvg } \\
\text { p value }\end{array}$ \\
\hline $\begin{array}{l}\text { Paran Jai Jaliya } \\
\operatorname{Re}(2009)\end{array}$ & 4.113256 & 0.004617 & 3.491065 & 0.000529 \\
\hline $\begin{array}{l}\text { Bolo Na Tumi } \\
\text { Aamar (2010) }\end{array}$ & 3.962306 & 0.000097 & 8.844865 & .00001 \\
\hline Paglu (2011) & 4.119201 & .000053 & 0.946479 & 0.177334 \\
\hline Awara (2012) & 4.641375 & 0.000019 & 0.280451586 & $<0.20$ \\
\hline $\begin{array}{l}\text { ChanderPahar } \\
\text { (2013) }\end{array}$ & -0.617318 & .270921 & NA & NA \\
\hline Bindaas (2014) & 5.98497 & $<.00001$ & 5.795563 & 0.000023 \\
\hline $\begin{array}{l}\text { ShudhuTomari } \\
\text { Jonyo (2015) }\end{array}$ & 0.613477 & 0.27136 & NA & $\mathrm{NA}$ \\
\hline Praktan (2016) & 1.878402 & 0.040656 & 2.588706 & 0.006735 \\
\hline $\begin{array}{l}\text { Amazon } \\
\text { Obhijaan (2017) }\end{array}$ & 4.288929 & 0.000127 & NA & NA \\
\hline $\begin{array}{l}\text { Hoichoi } \\
\text { Unlimited } \\
(2018)\end{array}$ & 4.640523 & $<.00001$ & $\mathrm{NA}$ & NA \\
\hline
\end{tabular}




\section{Discussion:}

From our experiment it can be showed that there exists colorism in Bangla Tollywood industry in selecting people for the leading cast. The experimental results showed that for $66.67 \%$ of the frames, the heroes have higher $\mathrm{L}^{*}$ values compared to male side characters and for $74.73 \%$ of the frames, the heroines have higher $L^{*}$ values with respect to the female side characters. The percentage of biasness is found to be for male lead cast selection and for female lead cast selection.

This work can be further extended to different language films of India to see whether colorism exists in those film industries. Whether different cultures and ethnicities in India practise colorism and discrimination based on skin tone can be achieved by taking reference from this work.

\section{References:}

1. Maddox, K.B. (2004). Perspectives on racial phenotypicality bias. Personality and social psychology review : an official journal of the Society for Personality and Social Psychology, Inc, 8 4, 383-401 .

2. Hunter, M. (2007). The Persistent Problem of Colorism: Skin Tone, Status, and Inequality.

3. Fink, B., Grammer, K., \& Thornhill, R. Human (Homo sapiens) facial attractiveness in relation to skin texture and color. Journal of Comparative Psychology, 115(1), 92 99. https://doi.org/10.1037/0735-7036.115.1.92(2001).

4. Srinivas, L. (2002). The active audience: spectatorship, social relations and the experience of cinema in India. Media, Culture \& Society, 24(2), 155173. https://doi.org/10.1177/016344370202400201

5. Jha, S., \& Adelman, M.(2009). Looking for Love in All the White Places: A Study of Skin Color Preferences on Indian Matrimonial and Mate-Seeking Websites. Studies in South Asian Film \& Media, 1(1), 65-83. https://doi:10.1386/safm.1.1.65_1

6. Shevde, N. (2008). All's Fair in Love and Cream: A Cultural Case Study of Fair \& Lovely in India. Advertising \& Society Review 9(2), doi:10.1353/asr.0.0003.

7. C. Connolly and T. Fleiss, "A study of efficiency and accuracy in the transformation from RGB to CIELAB color space," in IEEE Transactions on Image Processing, vol. 6, no. 7, pp. 1046-1048, July 1997.

8. Singh, P. (2014). Positive Psychology in the Indian Film Industry: A Promising Area of Research. Indian Journal of Positive Psychology; Hisar, 5(3), 329-331. 